\title{
An integrated assessment of climate-affected \\ long-term water availability and its impacts on energy security in the Ganges sub-basins
}

Xin Zhou a ${ }^{\text {* }}$, Bijon Kumer Mitra a , Devesh Sharma ${ }^{\text {b }}$, G.M. Tarekul Islam c, Rabin Malla d, and

Diego Silva Herran ${ }^{a}$

a Institute for Global Environmental Strategies (IGES), Japan

$b$ Central University of Rajasthan (CURAJ), India

c Bangladesh University of Engineering and Technology (BUET), Bangladesh

d Center of Research for Environment, Energy and Water (CREEW), Nepal

* Corresponding author. Email: zhou@iges.or.jp

\section{ABSTRACT}

The Ganges basin provides essential water for drinking, irrigation, industrial use and power generation. Global climate change will affect the water availability in the basin and inevitably intensify the competition for water among major users, particularly from thermal power generation. Knowledge on the spatial distribution of water supply-demand gaps and the water stress for meeting the cooling water requirements is crucial for effective energy planning and water resource management. This article presents the outcomes from the India case study based on an integrated assessment of the water-energy nexus in the Ganges sub-basins focusing on water stress assessment for thermal power plants up to 2050 under climate change conditions. The results from the hydrological modelling show that the overall water availability in the four studied sub-basins, namely Chambal, Damodar, Gandak and Yamuna, will increase by $13 \%, 33 \%, 21 \%$ and $28 \%$, respectively, in 2050 compared with the levels in 2010 under the greenhouse gas Representative Concentration Pathway (RCP) scenario 4.5. However, water availability will not be evenly distributed throughout the year and in some sub-basins water will be less available in the dry seasons. For example, Yamuna will have $25 \%$ less water in the dry season in the 2050s. Steady growth of water demand will cause serious water deficit in 30 out of 40 districts in Yamuna and 18 out of 33 districts in Gandak in 2050 under RCP 4.5. Consequently, 40\% of the existing and planned thermal power plants in Damodar and almost all in Gandak and Yamuna will face high water risks in the future, endangering the energy security in India. Energy development planning and water resource management therefore need to take into account the water risks posed to future thermal power generation and consider the relocation of the planned installations from water-stressed areas (particularly Gandak) to alternative locations with water surplus (such as Chambal). It is also important to adopt less water-intensive power generation technologies and cooling systems for the planned and new installations.

\section{KEYWORDS}

Ganges sub-basins, Integrated assessment, Water stress for thermal power generation, Water supply-demand gaps, Water-energy nexus

\section{DOI}

https://doi.org/10.30852/sb.2019.612

\section{DATES}

Received: 1 February 2019 Published (online): 6 June 2019 Published (PDF): 1 October 2019 


\section{HIGHLIGHTS}

» The results from the hydrological modelling for the Ganges sub-basins indicate that the overall water availability in Chambal, Damodar, Gandak and Yamuna will increase by $13 \%, 33 \%, 21 \%$ and $28 \%$, respectively, in 2050 ; however, it will vary across seasons and locations.

» In 2050, total water demand from irrigation, livestock, domestic, industrial and energy sectors as well as the environmental water requirement will increase steadily ranging from $34 \%$ (in Damodar) to $42 \%$ (in Yamuna).

» Among the four sub-basins, Chambal and Damodar will have water surplus at the district level; however, 18 out of 33 districts in Gandak and 30 out of 40 districts in Yamuna will face severe water deficit in 2050.

» Forty percent of the existing and planned thermal power plants in Damodar and almost all in Gandak and Yamuna are located in water-stressed or moderately water-stressed areas which will face high water risks in the future.

» Energy planners and investors should attach importance to the potential water risks posed to future energy security in India. The water stress assessment at the district level provided by this study can be used as effective information supporting thermal power generation planning and site selection.

\section{INTRODUCTION}

Water and energy sectors are intrinsically interdependent from both supply and demand sides. Water is required for extracting, refining and processing primary energy, such as coal, natural gas and oil, but used for the cooling system required for electricity generation and hydropower generation. Approximately $8 \%$ of globally withdrawn water is used for energy generation (Bhattacharya \& Mitra, 2013) and half of the world's thermal power plant capacity is threatened by water stress (Kressig, Byers, Friedrich, Luo, \& McCormick, 2018). On the other hand, energy is needed to power modern water supplies and wastewater treatment. Unstable operation of thermal power plants constrained by water shortage can in turn impact on pumping the water to the users. Insecurity in either sector will impact on the nexus of water and energy which can further generate a ripple effect on the whole economy. Until recently, sectoral approaches have been used to address the surge in demand for water and energy, but which ignore the inherent linkages between them. A systems approach for addressing the water-energy nexus challenges around the world is gaining importance among policymakers and academia in recent years (Delgado, Rodriguez, \& Sohns, 2015).

The Ganges basin is the world's second largest catchment area and home to more than 600 million people. It is a strategic river basin in South Asia providing more than $30 \%$ of the region's water resources (World Bank, 2015). The basin connects three riparian countries: Nepal, India and Bangladesh, and projected population growth together with rapid economic development will place great pressures on water resources here. The Ganges has been recognized as a water-stressed river basin, which issue will only heighten in the near future with the expected increase in water-intensive activities such as irrigation and thermal power generation. Rapid urbanization and the associated increase in water demand from households is another concern which may exacerbate water stress situation in the region.

The Ganges basin supplies water to thermal power generation systems with an installed capacity of more than $50 \mathrm{GW}$, accounting for more than $40 \%$ of the total thermal power capacity in the region (Sinha, 2014). Out of the total installed capacity, $92 \%$ uses coal with the wet cooling system which is the most water-intensive technology. Water stress will threaten the existing and planned thermal power plants located in this basin in the near future and up to 2050.

In addition, according to Gosain K., Rao, S., and Arora, A. (2011), the impacts of climate change on water resources are likely to affect irrigation, power generation and the environmental flows in dry seasons. The increasing pressures on water resources affected by climate change therefore threaten the livelihoods of $85 \%$ of the population in the Ganges basin that relies on agriculture and will harm the basin's long-term sustainable development.

Funded by the Asia-Pacific Network for Global Change Research (APN), we conducted a project entitled "Assessment of Climate-induced Long-term Water Availability in the Ganges Basin and the Impacts on Energy Security in South Asia" to help address the pressing challenges of water-energy nexus in the Ganges basin. The objective of the project is to provide an integrated assessment tool on water-energy nexus and inform relevant decision-makers and investors about water supply-demand gaps under the long-term impacts from climate change up to 2050 as well as the water stress for future thermal power generation in the Ganges basin. This article is prepared based on the methodology and the research results provided by the 
APN project.

The three case studies for India, Bangladesh and Nepal were conducted with different foci and level of detail. This article covers the case study for India, and provides a comprehensive assessment on water supply, water demand and water stress for existing and planned thermal power plants in four selected sub-basins. For the other two case studies, please refer to the full research report (Zhou et al., 2018).

Section 2 presents the analytical framework of an integrated assessment of water-energy nexus. Section 3 provides the results of the case study conducted for India and relevant discussions. Section 4 concludes the paper with policy implications.

\section{METHODOLOGY}

Water security and the nexus issues of water-energy-food-climate centred around water aroused great attention from business leaders and international society at the World Economic Forum 2008 (World Economic Forum, 2008), which has since inspired many research works in the nexus area. Some recent reviews have provided latest developments in the nexus research (Bazilian et al., 2011; Hamiche, Stambouli, \& Flazi, 2016; Endo, Tsurita, Burnett, \& Orencio 2017; Zhang, Chen, Li, Ding, \& Fu, 2018; Dai et al., 2018) by comparing the scope of the nexus issues (e.g., water-energy, water-energy-food, or water-energy-food-climate), scales (geographical and time), research objectives, issues focused on (e.g., water security, energy security, system performance), research methodologies (e.g., life cycle analysis, econometrics, computable general equilibrium modelling, system dynamics, or simulation and optimization models) and key messages, among the studies.

In this context, the present study focused on the issue of water scarcity as a threat to energy security in the sub-basins of the Ganges River. It mainly deals with the water-energy nexus focusing on the water risks of existing and planned power plants while taking into account the impacts of long-term climate change on water availability. For the methodology, this study developed a unique integrated, spatial assessment approach by combining the hydrological modelling of spatial water resource distribution and water demand assessment with field survey data collected from more than 20 thermal power plants in India. In addition to the desk research, this study conducted intensive consultations (five rounds in total) with various stakeholders including governmental organizations, thermal power plants, investors, NGOs and academia. The research objectives and methodology were the results of these consultations and the research outputs were conveyed effectively to relevant stakeholders. The methodology includes five modules, i.e. Water Supply Module, Water Demand Module, Energy Module, Water-Energy Nexus Assessment and the Water-Energy Nexus Assessment Web Tool (see Figure 1). Four sub-basins, namely Chambal, Damodar, Gandak and Yamuna, were selected

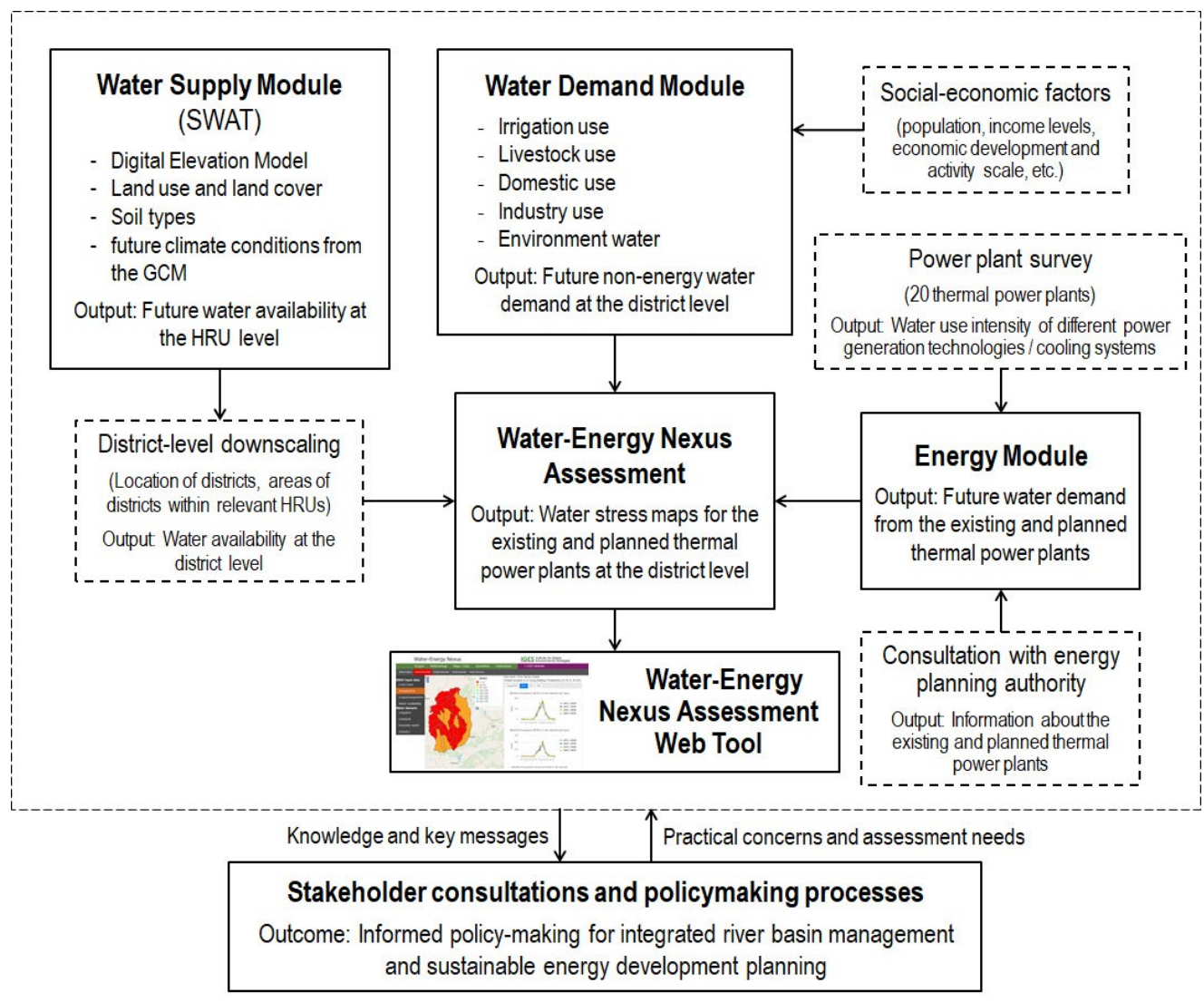

FIGURE 1. Methodological framework for an integrated assessment of the water-energy nexus under climate change impacts for the Ganges subbasins. 


\begin{tabular}{|l|l|}
\hline Data type & Data source \\
\hline $\begin{array}{l}\text { Digital Elevation } \\
\text { Model (DEM) }\end{array}$ & SRTM 90 m $\times 90$ m resolution \\
\hline $\begin{array}{l}\text { Land use and land } \\
\text { cover }\end{array}$ & $\begin{array}{l}\text { National Remote Sensing Centre } \\
\text { (NRSC) } 100 \mathrm{~m} \times 100 \mathrm{~m} \text { resolution }\end{array}$ \\
\hline Soil & $\begin{array}{l}\text { Food and Agriculture Organization } \\
\text { (FAO) gridded raster data 6500 } \mathrm{m} \times \\
\text { 6500 m }\end{array}$ \\
\hline Weather data & $\begin{array}{l}\text { Precipitation of o.5 degree } \\
\text { Temperature of } 1 \text { degree } \\
\text { Relative humidity, solar radiation, } \\
\text { wind grid, weather data http:// } \\
\text { globalweather.tamu.edu/ }\end{array}$ \\
\hline $\begin{array}{l}\text { Future climate } \\
\text { conditions from the } \\
\text { GCM }\end{array}$ & $\begin{array}{l}\text { MRI-CGCM3 model } \\
\text { http://pcmdig.llnl.gov/ }\end{array}$ \\
\hline
\end{tabular}

TABLE 1. Data used for the SWAT model.

based on the characteristics of current water supply and demand and the locations of the existing and planned thermal power plants.

Under the Water Supply Module, future water availability is projected for the four sub-basins using the Soil and Water Assessment Tool (SWAT), under future climate change conditions for the Intergovernmental Panel on Climate Change (IPCC) Representative Concentration Pathways (RCP) 4.5 and RCP 8.5 for the time period of 2020-2050 projected from a general circulation model (GCM), MRI-CGCM3 (Yukimoto et al., 2012). Major input data to the SWAT model including the Digital Elevation Model, land use and land cover, soil types, weather and future climate conditions from the GCM, etc., the relevant data sources of which are provided in Table 1 (for details, see Zhou et al., 2018).

The results from the SWAT model simulation on water supply and water availability are provided at the scale of hydrologic response unit (HRU) which is characterized by homogeneous land use, slope and soil type. To be consistent with the results from future water demand projections which are provided at the district level based on the statistics and other secondary information, the hydrological modelling results were then downscaled to the district level based on the following steps:

1. Identify the districts that are located within or across the borders of each HRU;

2. Calculate the area of each district and the areas located within different HRUs;

3. Use the water yield result of relevant HRU from the SWAT model as the representative value for the district area that is located within the HRU;

4. For water availability at the district level, multiply the water yield of the representative HRU by the corresponding area of the district and sum up for all relevant areas in the district.

Under the Water Demand Module, future water demand up to 2050 from four non-energy sectorsirrigation, livestock, domestic sector and industry sector - as well as environmental water, is estimated based on various methodologies taking into account population growth, income levels, economic development and activity expansion, etc. Adding up the sectoral water demand and the environmental water corresponds to the total non-energy water demand. The water demand from thermal power generation is estimated in the Energy Module.

Under the Energy Module, future water demand from thermal power generation (including both the existing capacity and the planned new capacity) is estimated. Information is collected on $\mathrm{i}$ ) the location of the existing and the planned power plants; ii) the type of power generation technology (such as coal-fired, gas-fired, oil-fired, hydro and other renewables) and the cooling system (open loop, close loop and dry cooling, etc.) for each of the existing and planned installations; and iii) the total annual electricity generation of each installation. Water use intensity of different technologies, i.e. the combination of the power generation technologies and cooling systems, is largely unavailable for the Ganges basin in extant literature. To obtain first-hand data, field surveys of 15 selected power plants in India and the questionnaire surveys of other power plants were conducted. With these input data, water demand from each of the existing and planned installations can be estimated. Water demand at the district level can be estimated by summing up the water demand of existing and planned installations that are located in a specific district.

Under the module of Water-Energy Nexus Assessment, water supply-demand balance is assessed at the district level by subtracting the total water demand (outputs from the Water Demand Module and the Energy Module) from the total water availability (outputs from the Water Supply Module). The ratio of water supply-demand balance is calculated at the district level by dividing the water supply-demand balance by the total water availability. The ratios are further classified into three categories, i.e. water-stressed area with the ratio value ranging between $(-, 0]$, moderate water-stressed area with the ratio value ranging between $(0,0.5]$ and water abundant area with the ratio value ranging between ( 0.5 , $+)$. The existing or the planned thermal power plants which are located in the water-stressed areas may face serious water shortage, which impacts on their operational stability. Water abundant areas can be considered as locations for the development of new energy projects in the future.

A free online tool was developed to enable spatial visualization of the data and the results in maps on water 


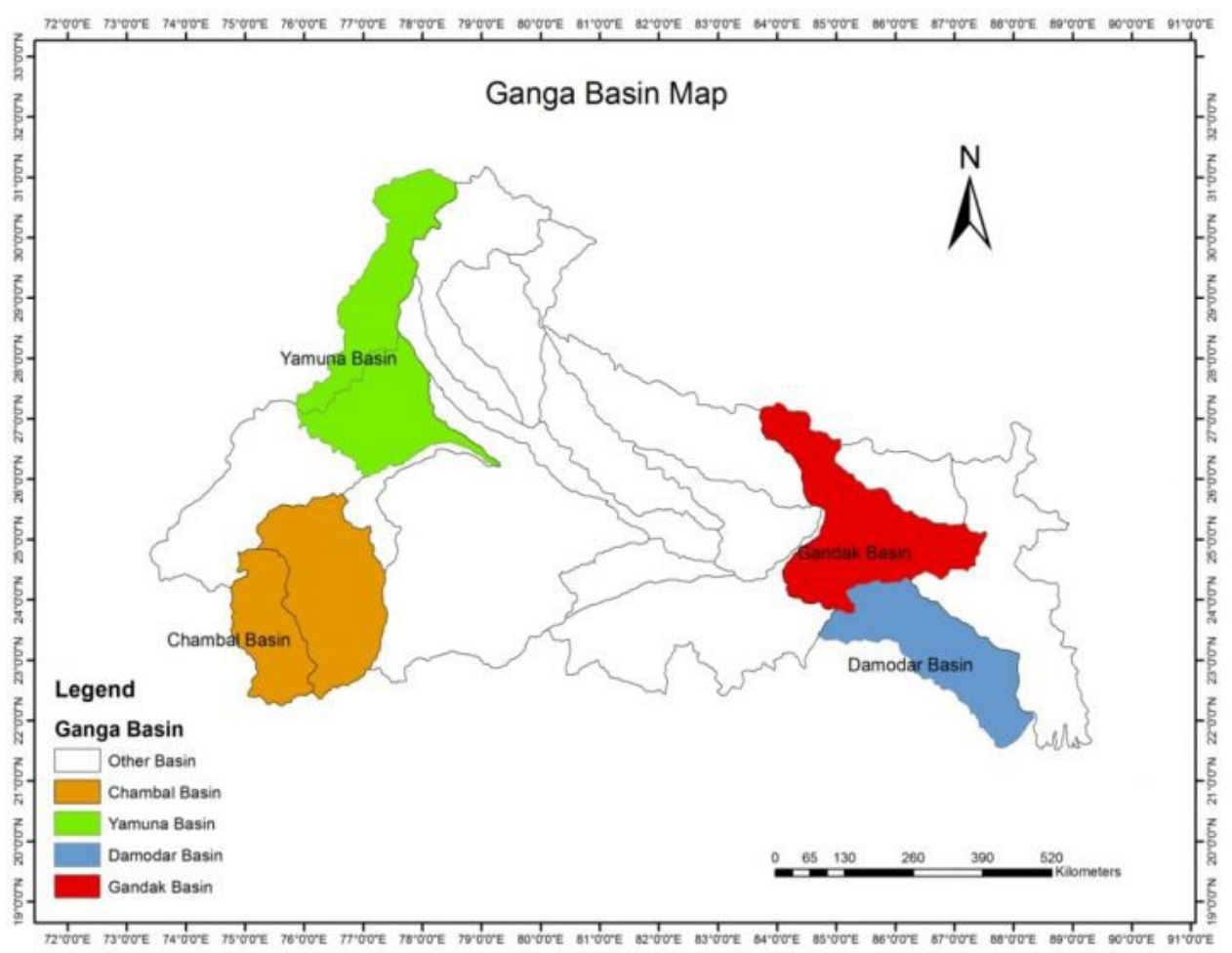

FIGURE 2. Location of Chambal, Yamuna, Gandak and Damodar subbasins in the Ganges basin.

supply, water demand and water-energy nexus assessment at the district level for the four sub-basins in India (forthcoming at IGES website).

To better inform the policymakers and relevant stakeholders on the spatial distribution of water stress particularly from the long-term energy security perspective, stakeholder consultations were conducted to communicate with them the research purpose and methodologies, collect feedbacks on the concerns and special assessment needs and convey the research results and key messages.

\section{RESULTS AND DISCUSSION}

\subsection{Water availability assessment for the four sub-basins}

Future water yield changes compared with the historical period (1976-2005) in the Chambal, Damodar, Gandak and Yamuna sub-basins (see the location of the four sub-basins in the Ganges basin in Figure 2) under
RCP 4.5 and RCP 8.5 at different time periods (2020s, 2030 s and 2050s) are presented in Table 2. Water availability will not be evenly distributed around the year and will vary from season to season depending on the physical conditions such as precipitation, evapotranspiration and surface runoff, etc. The results show that water availability will increase in Damodar and Gandak in both dry and wet seasons, particularly in Gandak in the wet season in 2030s under RCP 4.5 and in the 2050 s under RCP 8.5. However, it will decrease in Chambal in the dry season and Yamuna in both dry and wet seasons, particularly in the dry season in the 2050s under RCP 4.5 and in the wet season in the 2030s under RCP 8.5.

\subsection{Water demand assessment for four sub-basins}

Water demand from five sectors and the environmental water requirements in the four sub-basins for the base period 2010 and future periods (2030 and 2050) are presented in Figure 3. The results show that future water

\begin{tabular}{|c|c|c|c|c|c|c|c|c|c|c|c|c|c|c|}
\hline \multirow[t]{3}{*}{ Sub-basins } & \multirow{2}{*}{\multicolumn{2}{|c|}{$\begin{array}{l}\text { Historical } \\
1976-2005\end{array}$}} & \multicolumn{6}{|c|}{ Changes under RCP 4.5} & \multicolumn{6}{|c|}{ Changes under RCP 8.5} \\
\hline & & & \multicolumn{2}{|c|}{20205} & \multicolumn{2}{|c|}{20305} & \multicolumn{2}{|c|}{$2050 s$} & \multicolumn{2}{|c|}{$2020 s$} & \multicolumn{2}{|c|}{$2030 s$} & \multicolumn{2}{|c|}{$2050 s$} \\
\hline & Wet & Dry & Wet & Dry & Wet & Dry & Wet & Dry & Wet & Dry & Wet & Dry & Wet & Dry \\
\hline Chambal & 396.1 & 25.2 & 61.3 & -4.4 & 40.4 & -5.3 & 61.8 & -0.8 & 127.4 & 0.8 & 97.4 & -1.8 & 200.6 & 6.2 \\
\hline Damodar & 643.7 & 77.6 & 67.6 & -0.2 & 30.5 & 11.2 & 210.3 & 16.5 & 94.8 & 2.9 & 81.4 & 13.7 & 246.6 & 9.9 \\
\hline Gandak & 435.8 & 29.5 & 109.8 & 6.5 & 190.5 & 9.0 & 91.8 & 7.7 & 43.5 & 2.7 & 123.5 & 5.4 & 161.2 & 8.5 \\
\hline Yamuna & 233.9 & 37.1 & 104.3 & -6.6 & 42.4 & 6.5 & 84.4 & -9.1 & 30.8 & -11.5 & -16.6 & 1.0 & 155.7 & -7.0 \\
\hline
\end{tabular}

TABLE 2. Seasonal water yield changes in four sub-basins for different time periods and climate scenarios (in mm). Note: Wet season: June-October; Dry season: November-May. 


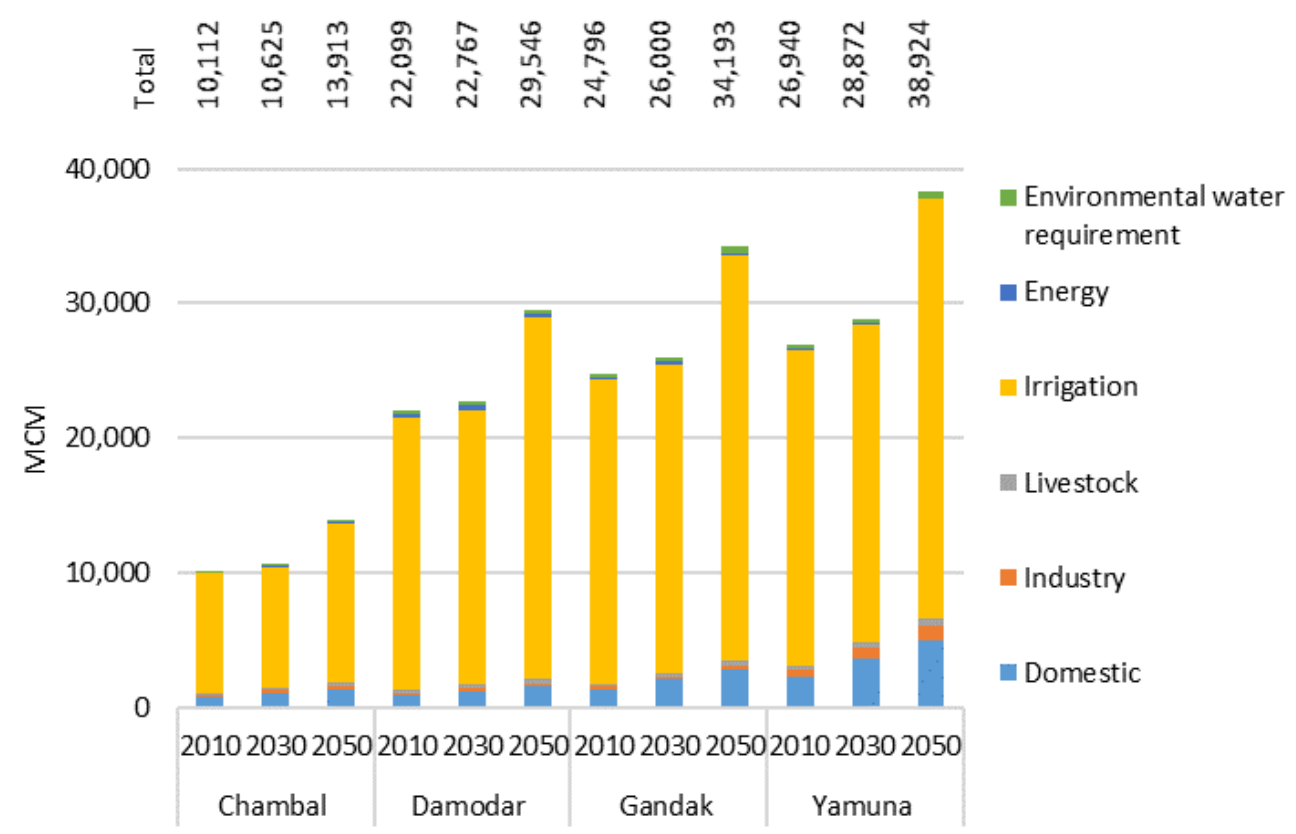

FIGURE 3. Sectoral water demand and future estimations in four sub-basins (in MCM).

demand will increase due to population growth, industrial development, increase in power generation and the expansion of irrigation. Out of the four sub-basins, Chambal will have the lowest water demand and Yamuna will have the highest. In all four sub-basins, irrigation water demand will dominate followed by domestic water demand and this trend will continue until 2050. In particular, Yamuna will have the largest irrigation water demand and the largest domestic water demand among the four sub-basins, followed by Gandak which will have the second largest water demand from both irrigation and domestic sectors. Energy water demand is the highest in Damodar followed by Gandak. Energy water demand will decrease in Chambal (from 66 million cubic meters, hereinafter referred to as MCM) in 2010 to 39 MCM in 2050) and Damodar (from 298 MCM in 2010 to $156 \mathrm{MCM}$ in 2050) and will maintain the same level in Yamuna (102 MCM). However, it will greatly increase in Gandak (from 71 MCM in 2010 to 182 MCM in 2050).

\subsection{Water stress assessment for four sub-basins}

Water stress is assessed based on the ratios of supply-demand balance, defined as the difference between total water availability and total water demand divided by the total water availability. The results are shown in the succeeding Figures 4, 5, 6 and 7. Water-stressed areas with ratio values ranging between $(-\infty, 0]$ are indicated in red; moderate water-stressed areas with ratio values ranging between $(0,0.5]$ are indicated in orange; and water abundant areas with ratio values ranging between $(0.5,+\infty)$ are shown in yellow. Locations of existing and planned power plants are marked as green stars.

The results of the water stress assessment at the sub-basin level indicate that Chambal and Damodar will have water surplus in the future. Chambal will have the largest water surplus among the four sub-basins. Both Yamuna and Gandak, particularly Yamuna, will face severe water deficit in the future.

At the district level, in general there will be more districts which will face water stress in the future, particularly in 2050. The level of water stress varies among the sub-basins. In Chambal and Damodar, particularly in Chambal, most of the districts will have water surplus (regions marked in yellow or orange) which will be able to satisfy the water demand not only for existing and planned thermal power plants, but also for new installations in the future. From a temporal viewpoint, Chambal will have more districts with water surplus while Damodar will have more districts, particularly in the southern part, facing water stress (turning from orange into red) in 2050 compared with the levels in 2010. However, in Gandak and Yamuna, most of the districts will face severe water stress (regions marked in red) in the future. From a temporal viewpoint, most of the districts in Yamuna face water stress in both 2010 and 2050 and the changes will be minor. However, Gandak will have more districts facing water stress (turning from orange into red) in 2050 compared with the levels in 2010. The existing and planned thermal power plants 

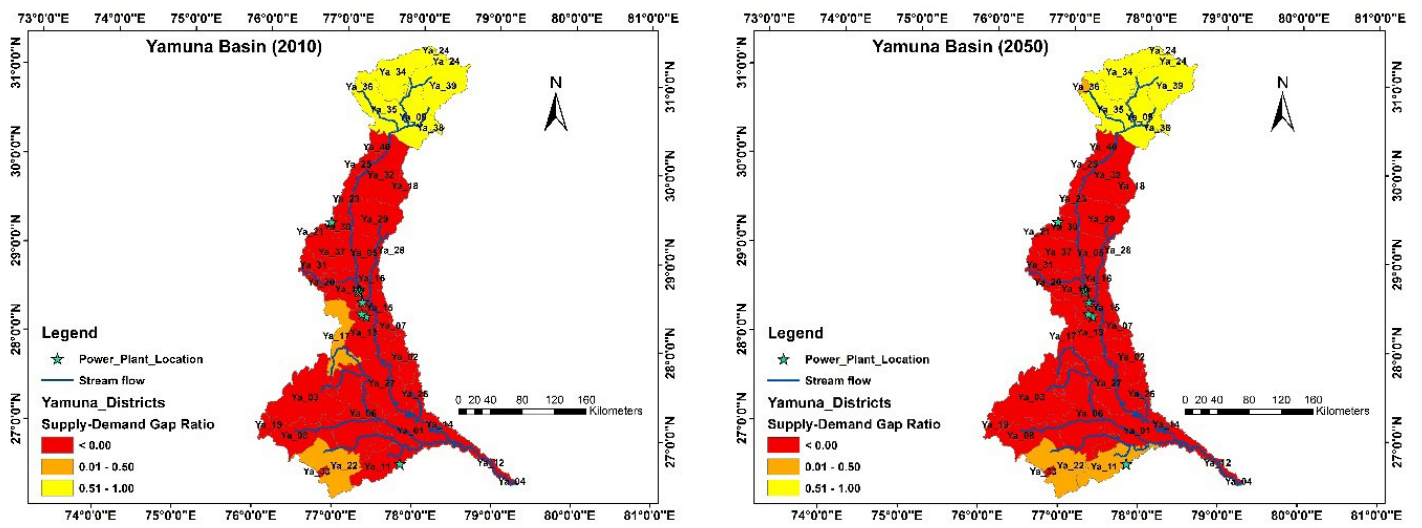

FIGURE 4. Sectoral water demand and future estimations in four sub-basins (in MCM).
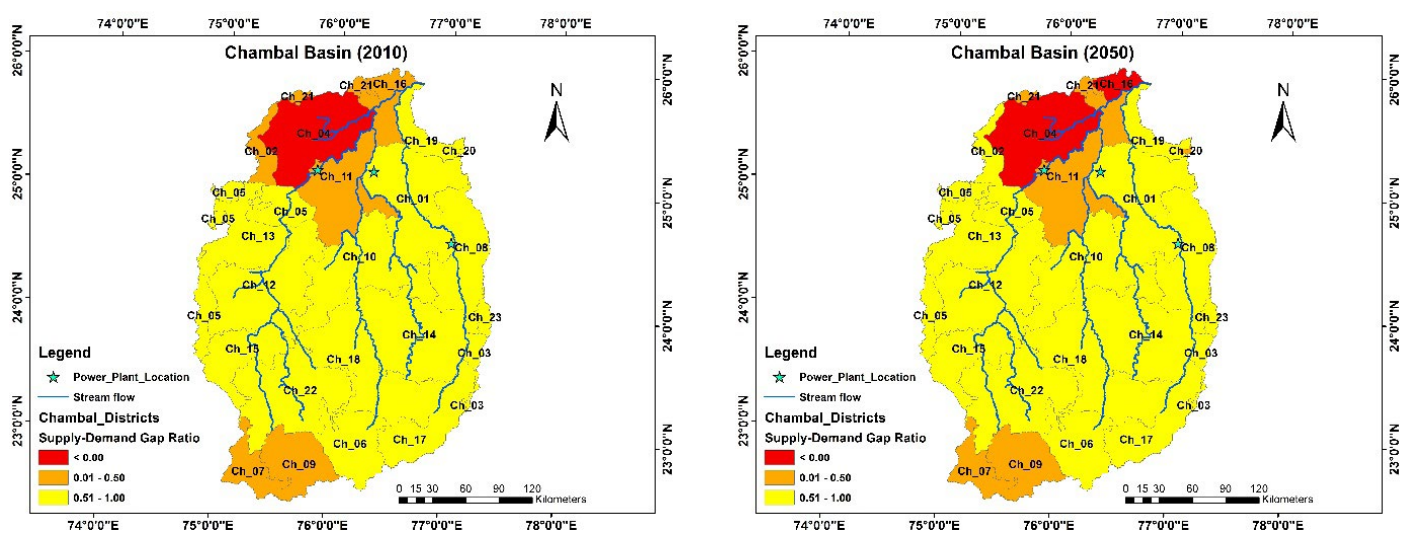

FIGURE 5. Water risk assessment for thermal power plants in Damodar.
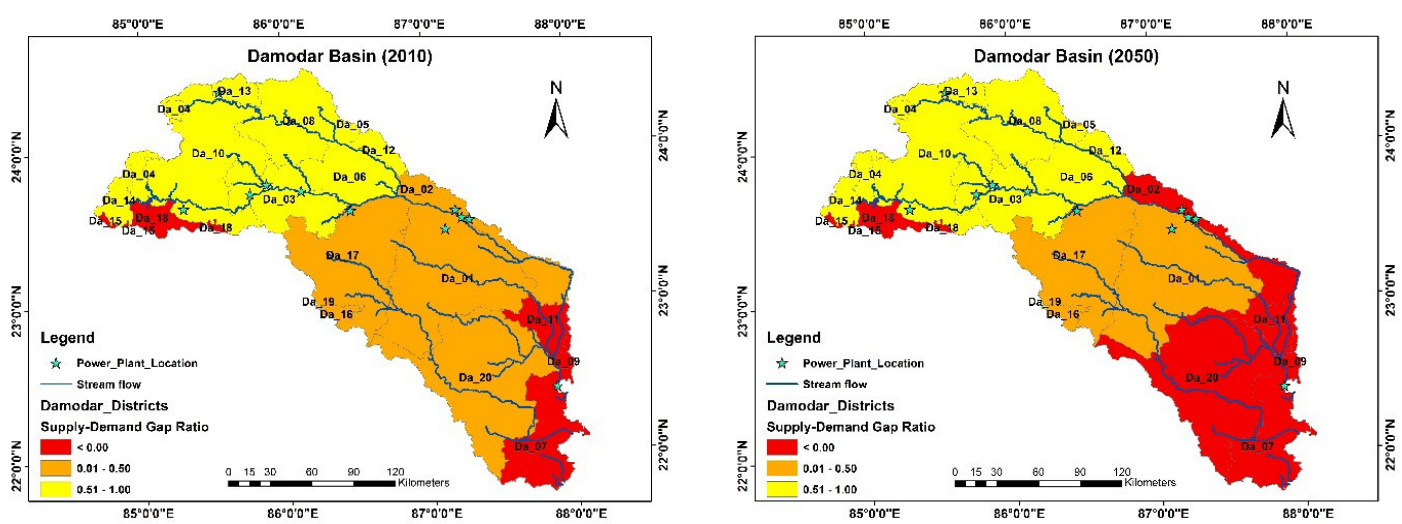

FIGURE 6. Water risk assessment for the thermal power plants in Gandak.
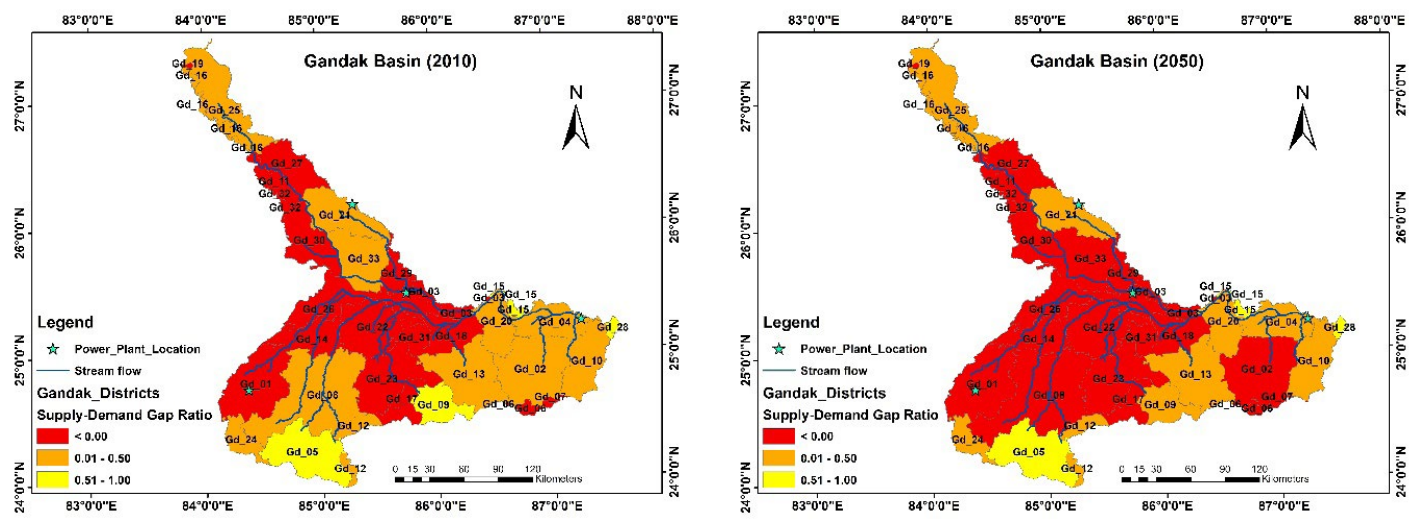

FIGURE 7. Water risk assessment for the thermal power plants in Yamuna. 
located in the water-stressed areas will face high risks. Particularly in Gandak, there will be many planned thermal power installations whose operation will face severe water shortage.

The existing or planned thermal power plants which are located in water-stressed areas may face serious water shortage and their operation will be adversely influenced. Water abundant areas (e.g., Chambal) can be considered as locations for new energy projects in the future.

\section{CONCLUSION}

The potential water risks for future energy supply were assessed considering the long-term impacts from climate change based on an integrated approach combining various modelling techniques and approaches, including the hydrological model and water demand projections for major water users (agriculture, domestic, industrial, energy, and environmental water requirements), as well as power plant field surveys. To inform decision makers, relevant stakeholders and investors on the spatial distribution of water stress particularly from the perspective of long-term energy security, we developed a free online tool for spatial visualization of the results on water supply, water demand, water supply-demand gaps and water risks for existing and planned thermal power plants in India at the district level for four studied sub-basins: Chambal, Damodar, Gandak and Yamuna.

From the supply side, the analyses showed that the overall water availability will increase in the four sub-basins in the future. However, the water availability will vary among different seasons. The water availability will increase Damodar and Gandak in both the dry and wet seasons, but will decrease in Chambal and Yamuna particularly in the dry seasons. From the demand side, future water demand in the four sub-basins will increase steadily, dominated by irrigation and followed by domestic water use. Of the four sub-basins, Chambal will have the least water demand while Yamuna will have the largest water demand. Energy water demand will be the highest in Damodar followed by Gandak whose demand will increase greatly in the future. For water supply-demand balance, Chambal and Damodar will have water surplus, while Yamuna and Gandak will face severe water deficit in the future. At the district level, most of the districts in Chambal and Damodar will have water surplus, which can be considered as appropriate locations for building new thermal power plants. However, 18 out of 33 districts in Gandak and 30 out of 40 districts in Yamuna will face serious water stress in 2050 . Consequently, $40 \%$ of existing and planned thermal power plants in Damodar and almost all in Gandak and Yamuna will face high water risks in the future. Considering the lifetime of 40 years or more, new thermal power installations constructed at the planned locations which are locked in the water-stressed areas will face severe water shortage in the future, which will greatly affect operational stability and thus endanger energy security in these sub-basins as well as in India. Relevant energy planning and water management organizations as well as investors need to factor-in the potential water risks for future thermal power generation and consider relocating the planned installations from water-stressed areas (particularly in Gandak) to alternative locations with water surplus (such as in Chambal). In addition, gradual transition to more water efficient options (high efficiency energy generation systems, dry cooling, renewable energy such as wind and solar) will reduce both water consumption and environmental impacts. Water conservation and enhancing water use efficiency from other major users, particularly from irrigation, the largest water consumer in the sub-basins, is also important in balancing water use by various users. Water rights and associated trading systems can be used as an economic incentive to help bring about more efficient water allocation and encourage water conservation and efficient use. However, the basic needs of the poor, particularly in rural areas, must be fully taken into account in related policymaking.

Due to the unavailability of published data, calibration and validation of the SWAT model was not fully performed by this study but cross-checked with other references. This is a major limitation of this study. Calibration and validation are critical factors influencing the reliability of the hydrological modelling results and need to be improved through future studies making use of observation data or other reference data from secondary sources. In addition, the present study can be further extended to cover all 19 sub-basins of the Ganges River by applying the district-level assessment approach developed for the India case study to provide a full picture of water risks for the energy security in the Ganges basin.

\section{ACKNOWLEDGEMENTS}

We would like to thank the Asia-Pacific Network for Global Change Research (APN) for providing the generous funding to support this research. Special thanks are given to Dr Linda Anne Stevenson, Ms Dyota Condrorini and Ms Nafesa Ismail who provided detailed guidance and various support throughout the implementation of the project. We extend our sincere thanks to the research assistants, Mr Sazzad Hossain, Dr Sawtantra Dubey and Mr Aashis Sapkota, who contributed to the 
three case studies. Grateful thanks are given to many stakeholders who attended the stakeholder consultation workshops and provided invaluable comments and feedbacks. We are also thankful to those power plants which provided relevant information and detailed data to support our field surveys. We sincerely thank Dr Hiroaki Shirakawa who helped develop the Water-Energy Nexus Assessment web tool. Finally, we would like to express our thanks to Dr Anindya Bhattacharya and Dr Pranab Barua who worked with the team to initiate this research project.

\section{REFERENCES}

Bazilian, M., Rogner, H., Howells, M., Hermann, S., Arent, D., Gielen, D., Steduto, P., Mueller, A., Komor, P., Tol, R. S. J., \& Yumkella, K. K. (2011). Considering the energy, water and food nexus: Towards an integrated modelling approach. Energy Policy, 39 (12), 7896-7906.

Bhattacharya, A., \& Mitra, B. K. (2013). IGES Report on water availability for sustainable energy policy: Assessing cases in South and South East Asia. Hayama, Japan: Institute for Global Environmental Strategies.

Dai, J., Wu, S., Han, G., Weinberg, J., Xie, X., Wu, X., Song, X., Jia, B., Xue, W., \& Yang, Q. (2018). Water-energy nexus: A review of methods and tools for macro-assessment. Applied Energy, 210, 393-408.

Delgado, A., Rodriguez, D. J., \& Sohns, A. A. (2015). Thirsty Energy: Understanding the linkages between energy and water. Live Wire, 2015/41. Washington, D.C., United States: World Bank. Retrieved from https://openknowledge.worldbank.org/handle/10986/21576

Endo, A., Tsurita, I., Burnett K., \& Orencio, P.M. (2017). A review of the current state of research on the water, energy, and food nexus. Journal of Hydrology: Regional Studies, 11, 20-30.

Gosain, A. K., Rao, S., \& Arora, A. (2011). Climate change impact assessment of water resources of India. Current Science, 101(3), 356-371.

Hamiche, A. M., Stambouli, A. B., \& Flazi, S. (2016). A review of the water-energy nexus. Renewable and Sustainable Energy Reviews, 65, 319-331.

Intergovernmental Panel on Climate Change. (2007). Climate Change 2007: The Physical Science Basis (IPCC Forth Assessment Report). Retrieved from https:// www.ipcc.ch/report/ar4/wg1/

Kressig, A., Byers, L., Friedrich, J., Luo, T. Y., \& McCormick, C. (2018). Water stress threatens nearly half the world's thermal power plant capacity (World Resources Institute's Blog Post, 11 April 2018). Retrieved from https://www.wri.org/blog/2018/04/water-stressthreatens-nearly-half-world-s-thermal-power- plant-capacity

Sinha, D. (2014). Reviving the Ganga, at the cost of its ecology! Retrieved from http://www.indiatogether.org/articles/ganga-river-waterway-reviving-and-impact-on-ecology-environment/ print

World Bank. (2015). The National Ganga River Basin Project. Washington, D.C., United States: World Bank. Retrieved from http://www. worldbank.org/en/news/feature/2015/03/23/ india-the-national-ganga-river-basin-project

World Economic Forum. (2008). World Economic Forum Annual Report 2007-2008. Geneva, Switzerland: World Economic Forum. Retrieved from http://www3. weforum.org/docs/WEF_AnnualReport_2007-08. pdf

Yukimoto, S., Adachi, Y., Hosaka, M., Sakami, T., Yoshimura, H., Hirabara, M., ... Kitoh, A. (2012). A new global climate model of the Meteorological Research Institute: MRI-CGCM3: Model description and basic performance. Journal of the Meteorological Society of Japan, 90A, 23-64.

Zhang, C., Chen, X., Li, Y., Ding, W., \& Fu, G. (2018). Water-energy-food nexus: Concepts, questions and methodologies. Journal of Cleaner Production, 195, 625-639.

Zhou, X., Mitra, B. K., Johnson, B., Herran, D. S., Sharma, D., Islam, G. M. T., \& Malla, R. (2018). Assessment of Climate-induced Long-term Water Availability in the Ganges Basin and the Impacts on Energy Security in South Asia (APN ARCP Final Report ARCP2015-13CMY-Zhou). 